\title{
O estudo do gasto público em meio ambiente
}

\section{A study on environment public spending}

\author{
Wellington Bueno ${ }^{1}$ \\ Fernando Oliana ${ }^{2}$ \\ Benilson Borinelli ${ }^{3}$
}

\section{Resumo}

Este texto trata da importância de se estudar o gasto público ambiental. Inicialmente se discute o conceito de gasto público ambiental e como ele se tornou uma função na contabilidade pública. Posteriormente se realiza uma análise de diversos estudos sobre o tema, de forma a proporcionar uma discussão sobre como o gasto público ambiental vem sendo alocado pelos governos. Na sequência, uma discussão sobre a relevância do assunto e da necessidade de mais pesquisas, uma vez que os investimentos em gestão ambiental ainda precisam ser melhor alocados e devidamente dimensionados. A transparência nos gastos públicos tem possibilitado a realização de mais estudos, permitindo que as questões ambientais sejam melhor observadas pela sociedade, além de revelar que estas questões ainda necessitam de uma maior atenção por parte dos governantes.

Palavras-chave: Gasto público. Contabilidade pública. Gasto ambiental.

\begin{abstract}
This text deals with the importance of studying environment public spending. Initially, we discuss the concept of environment public spending and how it became a public accounting function. Later, an analysis of several studies on the theme was carried out to promote a discussion on the environment public funds allocated by governments. Next, a discussion on the relevance of the theme and the need for further studies is presented, since investments on environment management still need to be better allocated and duly dimensioned. Currently, transparence in public spending has promoted the realization of more studies, leading to a more careful observation of environmental issues by the society, showing that these issues still need more attention from the goverment.
\end{abstract}

Key words: Public spending. Public Accounting. Environment spending.

\footnotetext{
${ }^{1}$ Professor do Departamento de Administração. E-mail: admwb@yahoo.com.br.

2 Departamento de Administração. E-mail: fernando.oliana@gmail.com.

${ }^{3}$ Professor do Departamento de Administração. Doutor em Sociologia pela UNICAMP.E-mail: bborinelli@hotmail.com.
} 


\section{INTRODUÇÃO}

Por décadas, a inadequada utilização dos recursos naturais não foi considerada uma questão relevante na agenda política, e, portanto, não era alvo da administração pública. O Estado, atrelado a uma visão de crescimento econômico, desenvolvia suas políticas públicas voltadas ao consumo de bens/serviços, com o objetivo estimular a geração de emprego e renda e de proporcionar a sociedade uma aparente melhoria na qualidade de vida. Contudo, no consumo destes bens/serviços, questões como a degradação (extração de recursos naturais para a produção) e a poluição (acumulo dos resíduos proveniente do consumo) somente ingressaram realmente na agenda política mundial a partir da década de 1970. Diversos desastres naturais e acidentes (nucleares, vazamentos de petróleo, contaminação por agentes químicos...) fizeram com que os governantes incluíssem em suas discussões a necessidade de políticas públicas com o objetivo de preservar e recuperar o meio ambiente.

Desta maneira surge a política ambiental moderna, e com ela o problema de como financiar esta política ambiental, uma vez que o tema recorrente nos fóruns e debates internacionais era sobre como alcançar o desenvolvimento sustentável. Apesar de toda a discussão sobre a compreensão e aplicabilidade do conceito de desenvolvimento (manter o crescimento econômico) sustentável (garantindo recursos naturais para as próximas gerações) as políticas públicas ambientais assumiram um papel relevante nas ações relacionadas às questões ambientais. Neste aspecto, 0 acompanhamento e a avaliação dos gastos ambientais vêm crescendo em importância, como meio de verificar, ao longo do tempo, a prioridade dada aos gastos ambientais em relação a outros gastos do governo.

Desde o inicio da década de 1990, vários países e organizações internacionais tem realizado esforços para medição do gasto na gestão ambiental. Um dos elementos fundamentais de um sistema integrado de contabilidade econômico-ecológica é o conceito de "Gastos Defensivos". Gastos defensivos podem ser entendidos como uma provisão de gastos para reparação do meio ambiente, a fim de atenuar, antecipar e prevenir os danos do processo econômico em sociedades industriais, ou causas que possam degradar o meio ambiente e condições de vida em geral (LEIPERT e SIMONIS, 1991).

A preocupação com a contabilidade ambiental foi evidenciada em 1998, quando a Comissão das Nações Unidas para o Desenvolvimento Sustentável estabeleceu um conjunto de procedimentos e princípios internacionalmente aceitos para contabilidade ambiental (JASCH, 2003). Estudos do grupo de pesquisas em gestão ambiental da Universidade Estadual de Londrina vêm levantando uma série de aspectos do financiamento público da gestão ambiental, com o objetivo de demonstrar o nível de investimentos neste setor e dar conhecimento aos governantes e a sociedade das tendências financeiras e fluxos de recursos nacionais.

Como a Lei de Contabilidade Pública Brasileira, Lei $n^{\circ} 4320 / 64$, não possuía uma classificação de gastos por função específica para a gestão ambiental, não há muitas informações anteriores ao ano 2000 sobre os gastos dos governos brasileiros com gestão ambiental, ou os dados não estavam 
disponíveis para a sociedade de forma consolidada e de fácil acesso. A partir do ano de 1999, com a criação da Portaria $n^{\circ}$ 042/99 do Ministério de Orçamento e Gestão (MOG), criou-se uma função específica para os desembolsos com Gestão Ambiental, relacionando suas subfunções, sendo que esta classificação deveria entrar em vigor a partir do exercício financeiro de 2000 para os orçamentos da União, dos Estados e do Distrito Federal, e do exercício financeiro de 2002, aos Municípios (PISCITELLI, TIMBÓ e ROSA, 1999 , p. 90). Esse avanço no detalhamento dos gastos governamentais possibilitou uma melhoria no levantamento e análise das contas públicas, permitindo ainda uma observação dos níveis de investimento em determinadas áreas e subáreas de governo, possibilitando que estudos informem a sociedade sobre o desembolso e a respectiva prioridade de cada governo.

Outra evolução na Administração Pública foi a Lei de Responsabilidade Fiscal, Lei $n^{\circ} 101 / 2000$ (LRF) criada em 2000. Este instrumento garante maior transparencia aos gastos públicos, facilitando a disponibilidade de informações para sociedade, através da internet. O uso intensivo do governo eletronico está permitindo maior transparencia das informações da gestão governamental. A Lei de Responsabilidade Fiscal e a Portaria $n^{\circ}$ 042/99 permitiram uma melhoria no processo de analise do financiamento público em gestão ambiental e, consequentemente, possibilitam o desmembramento de dados a fim de se estudar os gastos governamentais.

Neste contexto, verifica-se a emergência de um campo de estudo a respeito dos gastos públicos ambientais. Desta maneira, o objetivo deste texto é o de analisar a importância dos estudos sobre gastos públicos ambientais. Para esse fim, foram realizados: uma revisão sobre a literatura do gasto público e do gasto ambiental; uma analise de diversos estudos já realisados sobre o assunto; e uma analise sobre as possibilidades e tendências relacionadas aos estudos dos gastos públicos ambientais. Este estudo se justifica pela necessidade de mais análises sobre a dinâmica dos gastos públicos, da efetividade da política ambiental e da sua divulgação à sociedade. Para que se possa dar mais um passo a frente, rumo à definição de um montante ideal de alocação na função Gestão Ambiental, a fim de preservar e recuperar o meio ambiente. Porém, nota-se uma carência destes estudos, principalmente com relação aos gastos nacionais com o meio ambiente.

\section{GASTO AMBIENTAL PÚBLICO}

A Gestão Ambiental consiste na administração e no uso dos recursos ambientais, por meio de ações ou medidas econômicas, investimentos e potenciais institucionais e jurídicos, com a finalidade de manter ou recuperar a qualidade de recursos e desenvolvimento social. Envolve as atividades de planejamento, responsabilização, práticas, procedimentos e recursos para desenvolvimento social aliado à conservação ambiental. (CAMPOS, 2002)

Alguns marcos históricos da Gestão Ambiental Pública no Brasil foram:

- Criação do Conselho Nacional de Poluição Ambiental através do Decreto 303 de 1967; 
- Criação da Secretaria Especial do Meio Ambiente - SEMA e o Conselho Consultivo do Meio Ambiente - CCMA no âmbito do Ministério do Interior através do Decreto 73.030 em 1973;

- Estabelecimento da Política Nacional do Meio Ambiente através de Lei 6.938 de 1981, considerada por muitos o marco zero da consciência ambiental no Brasil;

- Criação do IBAMA e extinção da SEMA através da Lei 7.735 de 1989;

- Criação do Ministério do Meio Ambiente através da Lei 8.490 de 1992;

- Atualização da discriminação da despesa por funções de que tratam o inciso I do $\S 1^{\circ}$ do art. $2^{\circ}$ e $\S 2^{\circ}$ do art. $8^{\circ}$, ambos da Lei $n^{\circ} 4.320$, de 17 de março de 1964, estabelece os conceitos de função, subfunção, programa, projeto, atividade, operações especiais através da Portaria $\mathrm{n}^{\circ} 117$ de 1998;

- Reatualização da discriminação da despesa por funções de que tratam o inciso I do $\S 1^{\circ}$ do art. $2^{\circ}$ e $\S 2^{\circ}$ do art. $8^{\circ}$, ambos da Lei $n^{\circ} 4.320$, de 17 de março de 1964, estabelece os conceitos de função, subfunção, programa, projeto, atividade, operações especiais, através da Portaria $\mathrm{n}^{\circ} 42$ de 1999;

- Criação do Sistema Nacional de Unidades de Conservação (SNUC) através da lei $n^{\circ} 9.985$ de 2000 e sua regulamentação através do Decreto $n^{\circ} 4.340$ de 2002;

- Criação do Plano Estratégico Nacional de Áreas Protegidas (PNAP), através do Decreto $n^{\circ} 5.758$ de 2006.

A inclusão de preceitos ambientais na Constituição Federal de 1988, a exemplo da incorporação do conceito de desenvolvimento sustentável, da corresponsabilidade dos entes federativos pela qualidade ambiental e o direito de todos a um meio ambiente equilibrado, impactou os gastos públicos no país, por um lado, como nova destinação de recursos públicos e, mais adiante, por outro, também como uma nova fonte de recursos públicos (TRIDAPALLI et al., 2010).

Os diversos dispositivos constitucionais existentes que se referenciam ao meio ambiente, tratam de direitos e garantias da coletividade em relação ao meio ambiente, definem os recursos naturais que são bens da União e patrimônio público, e estabelecem as competências exclusivas e concorrentes dos entes federativos (União, Estados, Distrito Federal e Municípios) quanto à responsabilidade por preservar e gerir o uso racional e sustentável dos recursos naturais (CRUZ et al., 2009). A Constituição Federal brasileira estabelece que "todos têm direito ao meio ambiente ecologicamente equilibrado". Este princípio rege a política ambiental no país. Qualquer ato ou ação contrária a este princípio básico é ilegal. A carta magna estabelece ainda, que o princípio da sustentabilidade, impondo-se ao poder público e, à sociedade, o dever de defender e preservar o ambiente para as gerações, presente e futura; e o princípio da responsabilidade ambiental, imputando o ônus da recuperação dos impactos e danos ambientais ao agente causador dos impactos ou danos ambientais (FLORIANO, 2007). 
Na gestão da política ambiental, o Estado conta com um conjunto de instrumentos que combinam ações de comando e controle, como normas e legislações, zoneamentos, licenciamentos e fiscalização e de instrumentos econômicos, tais como taxas, impostos, permissões negociáveis de utilização, créditos subsidiados, isenções de impostos e outras facilidades contábeis para efeito da redução da carga fiscal. Segundo TRIDAPALLI, et al. (2010), os recursos destinados ao setor ambiental podem se originar de um número variado de fontes, tais como recursos ordinários do tesouro, compensações financeiras pela exploração de recursos naturais, taxas e multas pelo exercício de poder de polícia, empréstimos e doações internacionais e convênios com outros órgãos públicos. Essas fontes e o peso de cada uma no montante dos recursos à disposição dos órgãos e programas ambientais variam consideravelmente, em razão do nível de governo, do tamanho e riqueza do estado, da gravidade percebida dos problemas ambientais etc.

\section{O Controle dos Gastos Públicos no Brasil}

Segundo Baquero, et. al. (2006), gasto público é o desembolso realizado por uma entidade do governo, autorizada por autoridade competente, com o objetivo de cumprir interesses coletivos. É uma função do estado e constitui uma de suas ferramentas estatais mais importantes, uma vez que possibilita ao governo exercer um forte impacto sobre o desenvolvimento, seja por meio da criação de condições produtivas necessárias (bens públicos), da implantação de políticas de transferência que contribuam para diminuir a concentração de riqueza, ou através de ações que possibilitem amenizar os efeitos negativos das falhas de mercado. Os gastos públicos envolvem questões administrativas, políticas e ideológicas. Estes gastos demonstram como e onde são recolhidos e alocados os recursos públicos. Nesse sentido, torna-se necessário monitorar os gastos públicos efetivamente executados a fim de obter subsídios para controlá-lo de forma seletiva, tornando-o mais produtivo e eficiente.

A Constituição Federal de 1988 estabelece que o Estado Brasileiro deve assegurar o exercício dos direitos sociais e individuais, a liberdade, a segurança, o bem-estar, o desenvolvimento, a igualdade e a justiça, enfatizando-os como valores supremos da sociedade. No entanto, conforme afirma Botelho (2004, p. 36), "a ação do Estado para o suprimento das demandas da coletividade está condicionada à disponibilidade de recursos públicos". Sendo que o instrumento utilizado para definir a quantidade e destinação dos recursos do Estado é o orçamento público.

Juntamente com as receitas, os gastos integram a política fiscal do governo (BLANCHARD, 1999). Através deles, o governo estabelece suas prioridades no que se refere à prestação de serviços públicos básicos e aos investimentos a serem realizados. Gasto público é o dispêndio do governo na forma de custeio, investimento, transferência e inversão financeira, com o objetivo de cumprir as três funções governamentais: alocativa, distributiva e estabilizadora (GIAMBIAGI e ALÉM, 2007). As fontes de receita do Estado podem ser próprias ou de transferência. Entende-se como receitas próprias as arrecadações pelas entidades públicas em razão de sua atuação econômica no mercado (SECRETARIA DO TESOURO NACIONAL - STN) e como 
transferências as receitas provenientes do repasse de recursos captados por outras instituições ou instancias de governo (Rezende, 2001).

A Lei de Responsabilidade Fiscal (LRF), um instrumento de transparência que auxilia os governantes na gestão dos recursos públicos com regras claras e precisas, que são aplicadas em todas as esferas do governo, tanto da gestão da receita e da despesa pública como do endividamento e gestão do patrimônio público, permite análises do financimento público. Essa lei consagra a transparência da gestão pública, "através da publicação de relatórios e demonstrativos de execução orçamentária, apresentando ao contribuinte a utilização dos recursos que ele coloca à disposição dos governantes", segundo a Secretaria do Orçamento Feredal (2009). Também apresenta um conjunto com as normas e princípios: limites de gastos com pessoal; limites para o endividamento público; definição de metas fiscais anuais; mecanismos de compensação para despesas de caráter permanente; mecanismos de controle de finanças públicas em anos de eleição.

A LRF criou condições para a implantação de uma nova cultura gerencial, na gestão dos recursos públicos e incentiva o exercício pleno da cidadania, especialmente no que se refere à participação do contribuinte no processo de acompanhamento da aplicação dos recursos públicos e de avaliação dos seus resultados (STN, 2009). Esta norma legal em relação à prestação de contas públicas a partir da publicação de informações previstas pela LRF, estabelece regras que obrigam os entes federativos a apresentarem demonstrativos fiscais, que devem ser publicados em meio eletrônico, para que se tenha amplo acesso público. Assim a STN criou mecanismos de disponibilização das contas públicas consolidadas, inclusive de forma detalhada por função e subfunção permitindo aos cidadãos acesso à situação fiscal dos diversos governos (LOUREIRO, TEIXEIRA e PRADO, 2008), através de sites como os Portais de Transparência Pública da União e de seus órgãos, dos estados e dos municípios. Ainda segundo Loureiro, Teixeira e Prado (2008), não adianta as informações estarem disponíveis, é necessário que elas estejam apresentadas em uma linguagem acessível para que haja a efetiva transparência.

\section{Contabilidade Pública e o Gasto Ambiental}

É de suma importância para a análise dos gastos públicos, identificar os critérios de classificação das contas públicas. As classificações facilitam e padronizam o registro das ações do governo, possibilitando a visualização, por exemplo, do orçamento por poder, por funções de governo, por subfunções, por programas e por categoria econômica. A fim de se obter melhor compreensão dos dados, a contabilidade pública busca continuamente desenvolver normas que permitam atingir uma maior transparência dos atos públicos, tanto na informação quanto na publicação. Portanto, para se chegar ao nível atual a contabilidade pública passou por melhoramentos. A princípio, com a Lei de Contabilidade Pública 4.620/64, determinava o Anexo V a classificação das despesas orçamentárias por funções de governo. Em 04/02/1985, foi publicada a Portaria SOF n. ${ }^{\circ} 8$, que altera a classificação 
anterior e integra à Lei 4.320/64 estabelecendo uma nova classificação, passando de nove para dezesseis funções.

Segundo o Ministério do Planejamento, Orçamento e Gestão, a classificação funcional-programática representa uma junção de duas classificações: a classificação funcional oriunda da Lei $n^{\circ} 4.320 / 64$, que se propõe a explicitar "em que" as despesas estão sendo realizadas, e uma classificação de programas, com a preocupação de identificar os objetivos, isto é, "para que" as despesas estão sendo efetivadas, surgida a partir da introdução do orçamento-programa na prática administrativa brasileira (primeiro, em alguns estados como Rio Grande do Sul, e posteriormente, na União). Essa nova forma de classificação representou um grande avanço permitindo a vinculação das dotações orçamentárias a objetivos de governo que, por sua vez, eram viabilizados pelos programas de governo. Assim, visualizava-se o "que o governo faz", e não o "que o governo compra".

Embora a Constituição Federal de 1988 dispusesse sobre funções dos entes estatais em relação ao meio ambiente, a classificação dos gastos públicos não previa essa categoria. Até o exercício de 1999, a Classificação Funcional-Programática era constituída pelas Funções, Programas, Subprogramas, Projetos/Atividades e Subprojetos/Subatividades que não contemplavam de forma explícita o registro dos gastos públicos com gestão ambiental (PISCITELLI, TIMBÓ e ROSA, 1999). A partir do ano 2000, estabeleceram-se modificações no processo de planejamento e orçamento do setor público, a fim de privilegiar o aspecto gerencial do orçamento, com adoção de práticas simplificadoras e descentralizadoras (MPOG, 2012). Buscando aprimoramento, o governo brasileiro criou uma nova classificação Funcional-Programática no Orçamento Público, permitindo uma melhor visualização e avaliação adequada da aplicação dos recursos públicos. Esta nova estrutura de contabilização entrou em vigor no exercício financeiro de 2000 para a União, Estados e Distrito Federal, e a partir do exercício financeiro de 2002, para os Municípios (PISCITELLI, TIMBÓ e ROSA, 1999, p. 90).

A classificação funcional, por funções e subfunções busca mostrar em que área da ação governamental a despesa está sendo realizada. Dessa maneira "cada atividade, projeto e operação especial identificará a função e a subfunção às quais se vinculam". A função está relacionada com a missão institucional do órgão, por exemplo, cultura, educação, saúde, defesa, que guarda relação com os respectivos Ministérios ou Secretarias nos Estados e Municipios (SECRETARIA DO ORÇAMENTO FEDERAL, 2009).

Levando em consideração essa portaria, pode-se entender por "função o maior nível de agregação das diversas áreas que competem ao setor público". Seguindo essa mesma linha de raciocínio a contabilidade pública criou outros aperfeiçoamentos com intuito de alcançar as finalidades das funções. Foram criados desdobramentos nas funções e nos programas, representando os meios e instrumentos de ações articuladas para o cumprimento das funções. Dessa maneira, o programa agrupa também recursos humanos, materiais e institucionais e não só recursos financeiros (PISCITELLI, TIMBÓ e ROSA, 1999).

A aprovação das Portarias $n^{\circ} 117$, de 12-11-98, do Ministério do 
Planejamento e Orçamento, e $\mathrm{n}^{\circ} 42$ de 14-04-99, do Ministério do Orçamento e Gestão, consolidou e ampliou a classificação funcional dos gastos públicos, tornando explícita a combinação de subfunções com funções diferentes daquelas a que estejam vinculadas. A organização por funções tem por objetivo a programação, elaboração, execução orçamentárias e o controle da execução dos planos, as ações desenvolvidas direta ou indiretamente pelo Governo. A Portaria/MPOG n $42 / 99$ atualizou a discriminação da despesa por funções de que tratam no inciso I, do $\S 1^{\circ}$, do art. $2^{\circ}$, e $\S 2^{\circ}$, do art. $8^{\circ}$, ambos da Lei $n^{\circ}$ 4.320, de 17-03-64, estabelecendo novos conceitos de função, subfunção, programa, projeto, atividade e operações especiais (PISCITELLI, TIMBÓ e ROSA, 1999, p. 90). Após a aprovação da Portaria/MOG n 42/99, as funções do governo passaram de dezesseis para vinte e oito, sendo que a Gestão Ambiental foi inserido sob o código 18.

Com a nova classificação, os gastos com recursos hídricos, antes alocados na Função Energia e Recursos Minerais, passaram a ser alocados na função Gestão Ambiental. Contudo, os programas de abastecimento de água e esgotamento sanitário, inclusive usinas de tratamento de esgoto e tratamento do lixo sólido doméstico e hospitalar, foram incluídos na função Habitação e Urbanismo. Assim, a portaria definiu Gestão Ambiental como um conjunto de ações desenvolvidas para a proteção de recursos naturais, monitoramento por meio de levantamento sistemático de dados oceanográficos, meteorológicos, astronômicos e geofísicos, e controles das condições ambientais.

Outro detalhamento apresentado pela Portaria/MOG $n^{\circ} 42 / 99$ foi o das subfunções que representam uma partição da função, visando agregar determinado subconjunto de despesa do setor público. Para a função Gestão Ambiental foram criadas as subfunções:

541 - Preservação e Conservação Ambiental: Compreende as ações de planejamento, implantação, coordenação e manutenção que visam a defesa da fauna e da flora, a preservação e conservação de áreas e ecossistemas, a proteção de áreas urbanas e rurais contra possíveis danos causados por secas e inundações, bem como a proteção dos solos contra os desgastes ocasionados pelo homem ou pela natureza.

542 - Controle Ambiental: Compreende as ações destinadas a evitar e controlar a poluição das águas, do ar, do solo e sonora.

543 - Recuperação de Áreas Degradadas: Compreende as ações que visam aproveitar, para fins urbanos ou rurais, áreas constantemente alagadas ou sujeitas a erosão.

544 - Recursos Hídricos: Compreende as ações que objetivam o planejamento, coordenação, controle e supervisão do aproveitamento e utilização harmônica de recursos hídricos em múltiplas aplicações.

545 - Meteorologia: Compreende as ações visando a implementação, coordenação e manutenção de órgãos e mecanismos destinados ao estudo das variações climáticas e das condições meteorológicas. 


\section{Estudos sobre Gasto Ambiental no Brasil e Mundo}

Mesmo em nível internacional, o número de estudos sobre gastos ambientais do setor público parece ser relativamente pequeno e limitado. Contudo, segundo apurou Tridapalli (2010), existem estudos internacionais de grande valia para a análise da gestão ambiental governamental.

Bárcena et al (2002) estudou a participação dos gastos ambientais do setor público no PIB e per capita nos países Argentina, Brasil, México, Trinidad Tobago, Costa Rica, e Chile no período de 1992 a 2001. E evidenciou a necessidade de avaliar a viabilidade da criação de um sistema de pagamentos por serviços ambientais e melhorar a transparência nos custos de subsídios, assim como a incidência de impostos e barreiras ambientais no mercado.

Dougall e Huggins (2002) estudaram a participação dos gastos ambientais do setor público no PIB e per capita em Trinidad e Tobago. Tomando-se por base os gastos entre 1993 a 1999, e evidenciaram a dificuldade, tanto do setor público, quanto do setor privado, em apurar o real gasto ambiental, em razão do mesmo estar agregado ao operacional. Além da necessidade de padronizar os relatórios de transparência pública, principalmente quanto à área ambiental.

Gálan e Canal (2002) analisaram o perfil dos gastos ambientais públicos e privados e o sistema de coleta das informações da Colômbia, no período entre 1995 e 2001. Sua principal contribuição foi um reforço ao papel dos institutos de pesquisa, fundamentais para assegurar uma maior eficácia dos gastos com a gestão ambiental do país. Estes institutos estão em condições de continuar contribuindo nessa direção, mas de forma mais intensa e eficaz para o estabelecimento de políticas de utilização dos recursos naturais, orientando assim a evolução contínua das políticas ambientais.

López e Chudnovsky (2002) estudaram a participação dos gastos ambientais do setor público no PIB, no total do gasto público e o gasto ambiental por finalidade na Argentina, analisando-se o período de 1994 a 2000. Concluíram que o Tesouro Nacional financia a maior parte das despesas, enquanto a incidência de financiamento externo (que consiste principalmente em empréstimos) atingiu a média anual de 14\%. Em termos de instrumentos econômicos para gestão ambiental, cobra-se uma taxa única anual aos geradores e operadores de resíduos perigosos. Porém, várias províncias têm seus próprios registros, e algumas têm regras específicas, podendo aumentar as suas próprias taxas para o mesmo conceito.

Endara e Noboa (2005) verificaram a participação dos gastos ambientais do setor público no PIB e no total do gasto público do Equador em 1995, e mostraram uma grande inflexibilidade das finanças públicas do país e, uma forte dependência das empresas petrolíferas. Evidenciando ainda, que os governos locais não cumprem as tarefas ambientais descritas em seus planos de governo.

Merino e Tovar (2002) analisaram a participação dos gastos ambientais do setor público no PIB e no total do gasto público do México em 2000 e, concluíram que é precária a informação em todo o estado, e isto reflete a falta de transparência nas contas públicas em alguns casos. Os programas 
ambientais, em muitos casos se encontram espalhados em várias outras funções, dificultando a análise dos gastos públicos.

Vincent et al. (2002) verificaram a participação dos gastos ambientais do setor público no PIB, no total do gasto público e nos gastos públicos per capita da Coréia do Sul, Indonésia e Tailândia em 1997, apontaram que as despesas públicas relativas à gestão e proteção ambiental na Indonésia são extremamente baixas em relação aos níveis de outros países asiáticos, e esse índice vem piorando. Durante a crise econômica, o gasto ambiental caiu mais na Indonésia do que em outros países afetados. Isso fez decair as despesas a nível regional mais do que os cortes no orçamento nacional. Por conseguinte, a fatia dos gastos ambientais atribuídas às regiões diminuiu. Contudo, de acordo com as reformas de descentralização, que iniciaram no final de 1997, a participação regional deve aumentar e não decair. Assim, concluíram que não será possível uma melhoria da gestão ambiental na Indonésia, sem aumento da provisão de recursos humanos e financeiros.

Leipert e Simonis (1990) realizaram um estudo na Alemanha entre 1975 e 1985 sobre o valor dos gastos públicos e privados com reparação ambiental e mecanismos de controle, evidenciando estatisticamente o nível da estrutura do dano ambiental e as despesas de proteção, ou seja, sobre o dano ambiental em si e sobre os investimentos de proteção ambiental por parte da indústria e do governo, o capital social para a proteção ambiental, os custos totais de despesas e de proteção ambiental;

Pearce e Palmer (2001) analisaram a evolução da participação dos gastos ambientais do setor público no PIB dos Países da Europa e Ásia. E identificaram que a Coréia aumentou significativamente seus gastos em apenas seis anos, enquanto a República Checa mais do que dobrou suas despesas per capita no mesmo período. A Holanda, França e Suécia mostraram aumentos substanciais desde a metade da década de 1980. A Polónia mostrou um grande aumento durante a década de 1990.

Magnami (2000) pesquisou a desigualdade de renda com gastos ambientais nos países da União Européia entre 1980 e 1991 . Suas evidencias apontam que, quando há aumento da renda per capita, os habitantes de um país podem estar dispostos a pagar por melhor proteção ambiental. Contudo, a desigualdade de renda absoluta pode influenciar negativamente nos gastos ambientais, ou seja, países pobres gastam menos. Ficou comprovado que as despesas públicas com meio ambiente são afetadas pela variação da renda entre países.

Grand e D'Elia (2007) estudaram os países da América Latina e Caribe, verificando o grau de desenvolvimento humano (que inclui educação, esperança de vida e PIB per capita) e a pressão demográfica na explicação da disposição dos países em investir mais em meio ambiente.

Comparados aos indicadores dos gastos ambientais dos países da América Latina, estudos mostraram que o Brasil registra índices acima da média daqueles. Porém, os números ainda estão abaixo do registrado em países da Europa como a Alemanha e França. 
Os estudos sobre gastos ambientais no setor público brasileiro iniciaramse após o final dos anos 1990, destacando-se o nível de análise federal e as despesas totais, por função e por subfunções da gestão ambiental, carecendo de trabalhos mais consistentes sobre os gastos ambientais das esferas estadual e municipal. O pioneiro em estudos dos gastos públicos brasileiros foi o Instituto Brasileiro de Geografia e Estatística (IBGE), em 2001, sobre os gastos ambientais públicos de 1996 a 1998 nos três níveis administrativos. Young e Roncisvalle (2002) avaliaram os gastos em gestão ambiental, desde 1993 até o ano de 2000, como forma de avaliar as evoluções produzidas através da Conferência Rio-92. Concluíram que o setor público é o principal investidor em gestão ambiental, embora não houve uma evolução significativa nos valores gastos nesse período, opondo-se ao crescimento do PIB brasileiro que foi de $25,20 \%$. Avaliaram ainda que, aumentou o volume de recursos direcionados paras as despesas financeiras e administrativas, enquanto o volume para o pagamento de funcionários e para os investimentos de conservação decaiu. Lemos, Young e Geluda (2005), em seu estudo sobre os gastos públicos federais brasileiros encontraram evidências de descaso político em relação ao processo de alocação de recursos para área ambiental no Brasil.

Young apud Tridapalli (2006) ressaltam que o fato do setor público ser o principal investidor em gestão ambiental traz, como consequência, uma variação nas receitas destinadas para esta finalidade, em razão das políticas macroeconômicas, mudanças nas políticas fiscal e monetária etc, que podem implicar em cortes orçamentários nos programas governamentais, inclusive nos recursos destinados às políticas ambientais. Santos apud Tridapalli (2004) buscaram entender aspectos da estrutura de gestão ambiental no Brasil entre 1995 e 2002, avaliando aspectos da organização, das políticas ambientais, e da coordenação entre os níveis de governo. Os autores concluíram que, devido às dimensões continentais do Brasil, é importante descentralizar as ações da política ambiental e a destinação de recursos específicos para a gestão ambiental nos municípios.

Segundo Cruz et al (2009), de 2000, ano em que os gastos ambientais dos entes públicos passaram a ter uma rubrica específica como função de Governo, até 2008, o país destinou mais recursos para o pagamento de encargos da dívida do que para a gestão dos recursos ambientais que possui.

Os estudos de Silva Junior (2009) sobre a composição dos gastos públicos e crescimento econômico dos municípios brasileiros no período de 1991 a 2000, apontaram que quanto mais o governo gastou em nível municipal, em relação à renda local, maior foi o crescimento do município. Evidenciou-se, ainda, que os municípios brasileiros abaixo da linha de pobreza proporcionam um aumento muito maior no crescimento quando gastam correntemente do que os municípios que estão acima da linha de pobreza. Isso se dá pelo fato dos municípios pobres almejarem crescimento rápido, e com este objetivo, adotarem políticas de investir pesadamente em capital quando as necessidades da população carente são de curtíssimo prazo e/ou a caracterização de atividades econômicas de baixo dinamismo nos municípios pobres, onde a presença do Poder Público pode melhorar o bem-estar com a estimulação das atividades econômicas do município mediante geração de empregos e demanda por bens e serviços produzidos pelo setor privado. 
A análise do nível de sustentabilidade das unidades federativas do Brasil e de suas capitais, sobre as perspectivas econômica, social e ambiental realizado por Macedo et al (2010), mostraram que o Distrito Federal e a cidade de Vitória no Espírito Santo são as cidades que alcançaram os melhores níveis de sustentabilidade em todos os modelos (perspectivas), sendo considerados os de melhor nível de desenvolvimento sustentável, em todas as perspectivas conjugadas: ambiental, social e econômica. Do outro lado do ranking de sustentabilidade aparecem o estado do Maranhão e a cidade de Maceió em Alagoas, como as localidades problemáticas sob praticamente todas as perspectivas no que diz respeito ao desenvolvimento sustentável. Uma questão relevante, que surgiu da comparação destes rankings é a posição dos estados de Alagoas e do Piauí, que possuem enquanto estados, desempenhos ruins e que têm suas capitais também com baixo nível de sustentabilidade. Esta é realmente uma situação preocupante e que merece uma intervenção urgente, com o desenvolvimento de políticas públicas que envolvem as instâncias municipal, estadual e federal.

Os resultados encontrados pelo estudo dos gastos com meio ambiente no Brasil de Nascimento Junior (2011), comparando o valor do dano ambiental e a destinação de recursos públicos para a recuperação no período de 2000 a 2009, demonstrou que o governo não gasta o que deveria para recuperar os danos ambientais causados ao meio ambiente, e ainda, que esses gastos são pequenos se comparados com os danos calculados. Ressalta-se que estes gastos deveriam ser construídos com base em parâmetros orçamentários estimados nos danos causados aos biomas degradados, o que não se verificou nas análises realizadas. O estudo verificou ainda que, os gastos realizados não cresceram durante o período, o que demonstra não existir uma continuidade do gasto e, consequentemente, de sua manutenção, apesar da evolução dos danos ambientais.

\section{Por que estudar o Gasto Ambiental}

A criação da Lei de Responsabilidade Fiscal e a adoção de mudanças na apresentação da contabilidade pública no Brasil no final dos anos 1990, quando foi estabelecida a padronização e transparência dos demonstrativos econômicos, permitiram um estudo mais aprofundado sobre as políticas de gastos públicos. Esses avanços na administração governamental permitiram estudar diversos índices sobre diversas óticas nos âmbitos nacional, estadual ou municipal, e foram fundamentais para o acompanhamento mais detalhado dos gastos ambientais do setor público no país. Esses estudos possibilitam compreender as diretrizes, conceitos, objetivos, ferramentas e estratégias da gestão pública e auxiliam na busca de melhorias da gestão das áreas protegidas.

As despesas com a função Gestão Ambiental diminuíram ao longo dos últimos anos, contradizendo as discussões atuais acerca da preservação dos recursos ambientais que, diante do presente estágio de degradação, têm enfatizado a necessidade de investimentos para preservação dos recursos existentes. O orçamento previsto para o gasto com a gestão ambiental no país normalmente não é executado. O valor previsto inicialmente para esse gasto, quando não executado, é utilizado no custeio de despesas de outras funções, refletindo o descaso político na questão ambiental. Um estudo sobre essa questão traria à luz as políticas ambientais do administrador público, 
levantando-se o montante orçado confrontando-se com o realizado e sobre o valor não utilizado repassado à outra dotação, averiguar-se-ia, assim, as prioridades da gestão, apontando-se ainda, as possíveis deficiências na gestão ambiental pública, onde certamente se faria necessário o investimento ora repassado à outra função.

O estudo dos gastos públicos em gestão ambiental é uma tentativa de mensurar as ações produzidas pelos órgãos públicos sobre o meio ambiente. Contudo, a escassez de indicadores confiáveis reprime a expansão da análise da eficiência dos gastos públicos. Segundo Tridapalli et al (2010), é através dos estudos que observam-se quais paradigmas sociais e econômicos, projetos, setores, regiões, políticas e pessoas são efetivamente priorizadas ou não. Por meio da análise de gastos públicos, é possível monitorar, comparativa e historicamente, as oscilações em termos do tratamento e das prioridades entre as instituições ambientais, os setores governamentais, os governos, os ciclos eleitorais, os partidos, os grupos de poder, personalidades e os períodos históricos. O gasto em gestão ambiental é menos perceptível e, demanda um prazo maior se comparado aos gastos em outras funções. Objetivando um maior apelo social e eleitoral, os gestores, quando da escassez orçamentária, priorizam os gastos em outras funções, que muitas vezes geram sérios impactos ambientais. A instabilidade nos gastos ambientais dificulta o estudo fidedigno dos gastos públicos. Soma-se a isso a dificuldade de se encontrar informações disponíveis à comunidade.

As pesquisas sobre gastos auxiliam na transparência das ações dos governantes para a sociedade, disponibilizando à população os valores gastos, as aplicações, destinações, prioridades, para que a sociedade saiba onde seus impostos estão sendo empregados e verificar o cumprimento das promessas de campanha dos políticos. Os gestores, por sua vez, cientes da evolução da transparência pública, utilizarão os recursos com maior eficácia e a população, devido à notoriedade dos gastos, pode repensar suas ações de consumo incontrolável.

Através dos estudos sobre gastos é possível desvendar as reais necessidades de investimento no meio ambiente, face às ações já destinadas. Sabendo-se das carências, é possível levantar-se o estudo da situação de determinada região, evidenciando suas evoluções e suas carências, destinando-se os recursos na função e subfunção específicas. No estudo das práticas observa-se se a legislação aplicada às empresas, ao setor público e aos usuários condiz com a realidade. Assim, caso seja necessário uma adequação às normas, os estudos podem ilustrar as políticas necessárias. Visualiza-se a existência de disparidades entre micro e macro regiões, cidades, estados, países, analisando-se boas práticas que possam ser aplicadas a outras organizações. As descobertas podem auxiliar na padronização de modelos sustentáveis, relatórios gerenciais, políticas públicas, dentre outros.

O estudo pode trazer também soluções, como propor meios alternativos que estimulem aos detentores de recursos naturais a auxiliarem na preservação de seus territórios, haja vista o meio ambiente ser um bem comum à sociedade. Trabalhando com os diversos resultados, pode-se estudar qual o valor a destinar aos programas nos próximos orçamentos, as relações entre a evolução do gasto ambiental e o PIB, ou o gasto total, ou o gasto per capita, ou ainda outras comparações que possam auxiliar na análise dos dados. 
Permitem ainda a comparação das evoluções entre as regiões, cidades, estados, países, apontando possíveis causas para a divergência de números ou para a similaridade destes e as variações durante períodos predeterminados. Analisa-se o custo-benefício do gasto público ambiental a médio e longo prazo. Verifica-se as variáveis na disponibilização dos recursos, como o impacto das crises econômicas, guerras, contenção de despesas, desigualdade econômica e social, tamanho e disponibilidade de recursos naturais, o crescimento da localidade, enfim analisa-se os fatores que podem explicar a disposição dos governantes em investir em meio ambiente.

\section{CONSIDERAÇÕES FINAIS}

Através deste estudo pode-se observar que o gasto público com o meio ambiente surgiu da necessidade de se investir na conservação e recuperação do meio ambiente. A Contabilidade Pública teve que ser adaptada para dar conta desta nova situação, criando novas funções e subfunções. Outra característica a ser ressaltada é a implantação, pela LRF, da transparência na gestão do gasto público, facilitando as pesquisas sobre o assunto.

Os diversos estudos apresentados mostram que os gastos públicos sofrem diversas influências, e que o gasto público ambiental é fortemente afetado por diversas outras políticas, consideradas como prioritárias pelos governos.

As possibilidades de pesquisa, aqui apresentadas, refletem a necessidade de se averiguar a qualidade das políticas públicas relacionadas ao meio ambiente, e de se buscar verificar os montantes realmente necessários para fazer frente às questões que o problema ambiental representa.

Desta maneira, estudar o gasto ambiental implica em verificar as ações produzidas pelo gasto público ambiental, e disponibilizar à sociedade informações sobre o gasto ambiental e como ele foi alocado, de forma a permitir uma evolução na transparência pública, além da necessidade de se encontrar o investimento adequado, possibilitando políticas públicas realmente efetivas. Assim como, o estudo do gasto ambiental pode auxiliar as sociedades a preservar seus territórios e a melhorar a disposição dos governantes na alocação dos recursos necessários ao meio ambiente.

\section{REFERÊNCIAS}

BÁRCENA, A., MIGUEL, C. J. de, NÚNEZ, G., GÓMEZ, J. J., ACQUATELLA, J., ACUÑA, G. Financiamiento para El desarrollo sostenible en América Latina y el Caribe De Monterrey a Johanesburgo. Santiago de Chile: Organização das Nações Unidas - Comisión Económica para América Latina - CEPAL, 2002.

CHUDOVSKY, D., \& LÓPEZ, A. Gasto, Inversión y Financiamiento para el Desarrollo Sostenible en Argentina. Santiago de Chile: Organização das Nações Unidas - Comisión Económica para América Latina - CEPAL, 2002

CRUZ, C. F; MARQUES, A. L; FERREIRA, A. C. S. Informações Ambientais na Contabilidade Pública: Reconhecimento de sua Importância para a Sustentabilidade. Revista Sociedade, Contabilidade e Gestão, Volume 4 Número 2, 2009.

DOUGAL, D., \& HUGGINS, W. Expenditures, investment and financing for sustainable development in Trinidad and Tobago. Santiago de Chile: Organização das Nações Unidas Comisión Económica para América Latina - CEPAL, 2002. 
ENDARA, N. G., \& NOBOA, S. J. El financiamiento del desarrollo sostenible en El Ecuador. Santiago de Chile: Organização das Nações Unidas - Comisión Económica para América Latina - CEPAL, 2005.

FILHO, J. G. M. Gestão Ambiental Pública. Secretaria de Estado de Desenvolvimento Sustentável de Santa Catarina. Disponível em http://www.sds.sc.gov.br/index.php?option=com docman\&task=doc download\&gid=329\&lang= . Acesso em 28/04/2012

FILHO, M. R. dos S; FILHO, J. M. D; FERNANDES, G. B. Avaliação da Capacidade de Predição do Índice de Desenvolvimento Humano dos Municípios (IDH-M) a partir das Demonstrações Contábeis e Legais. XXXIV Encontro da ANPAD, 2010. Disponível em http://www.contabeis.ufba.br/Site/arquivos/Editor/file/Mestrado/Artigos/2010/Artigo ENANPAD2 010 Manuel.pdf. Acesso em 26/04/2012.

FLORIANO, E. P. Políticas de Gestão Ambiental. UFSM-DCF, $3^{\circ}$ edição. Santa Maria, 2009.

GÁLAN, F. A.; CANAL, F. J. Gasto, inversión y financiamiento para El desarrollo sostenible en Colombia. Santiago del Chile: Organização das Nacões Unidas - Comisión Económica para América Latina - CEPAL, 2002.

GRAND, M. C., \& D'ELIA, V. La política ambiental en América Latina y el Caribe: ¿de qué depende? CEMA Working Papers: Serie Documentos de Trabajo. 366, Universidad del CEMA, 2007. Disponível em http://www.ucema.edu.ar/publicaciones/download/documentos/366.pdf. Acesso em 13 de maio de 2012.

INSTITUTO DE PESQUISA ECONÔMICA APLICADA. Como anda o investimento no Brasil? Comunicado IPEA, 2011.

LEIPERT, C.; SIMONIS, U. E. Environmental Protection Expenditures-The German Example. The Environmentalist, Berlin-Germany, 10(4), 301-304, 1990. Disponível em http://www.springerlink.com/content/7274491u7542t667l. Acesso em 13 de maio de 2012.

LIMONT, M. et al. Educação no Processo de Gestão Ambiental Pública: concepção e prática educativa na capacitação em gestão participativa de unidades de conservação no domínio sul da Mata Atlântica. IV Encontro Nacional da ANPPAS, 2010.

MACEDO, M. A. S; CIPOLA, F.C.; FERREIRA, F.R. Análise do Nível de Sustentabilidade das Unidades Federativas do Brasil e de suas Capitais: Um Estudo sob as Perspectivas Econômica, Social e Ambiental. SIMPOI, 2010.

MERINO, G., \& TOVAR, R. Gasto, inversión y financiamiento para El desarrollo sostenible en México. Santiago del Chile: Organização das Nações Unidas - Comisión Económica para América Latina - CEPAL, 2002.

MPOG - MINISTÉRIO DO PLANEJAMENTO, ORÇAMENTO E GESTÃO. Classificações Orçamentárias. Disponível em http://www.planejamento.gov.br/secretaria.asp?cat $=51 \&$ sub $=130 \& s e c=8$. Acesso em 26/04/2012.

NASCIMENTO JUNIOR, E. R. do. Gastos com meio ambiente no Brasil: Uma Comparação entre o Valor do dano e a Destinação de Recursos Públicos para sua Recuperação no período de 2000 a 2009. Dissertação (Mestrado) - Universidade de Brasília, 2011.

ORAIR, R. O. Especificidades do Processo Orçamentário Brasileiro e os Obstáculos à Harmonização Contábil: uma análise aplicada aos investimentos das administrações públicas. XVI Prêmio Nacional da Secretaria de tesouro Nacional, 2011.

PEARCE, D., \& PALMER, C. Public and private spending for environmental protection: a crosscountry policy analysis. Fiscal Studies, 22, 403-456, 2001. Disponível em http://www.ifs.org.uk/fs/articles/0048a.pdf. Acesso em 13 de maio de 2012.

PREFEITURA DO MUNICÍPIO DE MANAUS: Portaria $n^{\circ} 042$ comentada. Disponível em http://www2.manaus.am.gov.br/portal/transparencia/ContasPublicas/outrosinslegais/portaria 42 comentada.pdf. Acesso em 01/05/2012. 


\section{PRESIDÊNCIA DA REPÚBLICA - CASA CÍVIL: CONSTITUICCÃO DA REPÚBLICA}

FEDERATIVA DO BRASIL DE 1988. Disponível em:

http://www.planalto.gov.br/ccivil 03/Leis/L6938.htm. Acesso em 20/10/2010.

RIBEIRO, F. C. S, et al. A Evolução do Produto Interno Bruto Brasileiro entre 1993 e 2009. FAE Vitrine da Conjuntura, 2010. Disponível em

http://www2.fae.edu/galeria/getlmage/1/1395677446523294.pdf. Acesso em 29/04/2012.

SILVA, C. M. V. S; FILHO, F. B. B; TAKAGI, M. Metodologia sobre Gasto Público Rural. Revista do Instituto de Estudos Agrários e Combate à Pobreza. Distrito Federal, Volume 3, Numero 1, 2009.

SILVA JUNIOR, R. L. S. Composição dos Gastos Públicos e Crescimento Econômico dos Municípios Brasileiros. Dissertação (Mestrado) - Universidade Católica de Brasília, 2009.

TRIDAPALLI, J. et al. Análise dos Gastos Ambientais no Setor Público Brasileiro:

Características e Propostas Alternativas. Maio, 2010.

VINCENT, J. R. et al. Public environmental expenditures in Indonesia. Bulletin of Indonesian Economic Studies, 38, 61-74, 2002. Disponível em http://wwwwds.worldbank.org/servlet/WDSContentServer/WDSP/IB/2001/08/29/000094946 01081504110 225/Rendered/PDF/multiOpage.pdf. Acesso em 09 de maio de 2012. 